\title{
SEXUALIDADE INFANTIL NO SÉCULO XXI: ENTRE LACUNAS E POSSIBILIDADES
}

\author{
Maria José Barbosa de Andrade ${ }^{1}$ \\ Maria Thaís de Oliveira Batista ${ }^{2}$ \\ Geane de Andrade Pinheiro ${ }^{3}$
}

\begin{abstract}
RESUMO. São muitas as experiências vividas em nosso cotidiano, que nos mostram a existência de tabús e preconceitos em relação à sexualidade no contexto atual, tanto na sociedade, quanto na escola. Estes preconceitos e tabús são advindos de uma herança cultural que existe desde os primórdios da humanidade. A quebra dessses tabús relacionados a essa questão devem estar inseridos nas práticas pedagógicas do contexto escolar, de forma que descarte todas as falácias sobre o tema como algo pecaminoso. É desse modo que o presente artigo tem como finalidade levantar propostas de como trabalhar a temática de sexualidade no contexto escolar, tendo sido elaborado a partir de uma pesquisa de campo realizada com duas sujeitas de pesquisa - uma mãe e uma professora de uma escola pública municipal da cidade de Poço José de Moura. Os resultados nos mostram que a dificuldade de se ter um trabalho eficaz sobre esta temática, deve-se a uma falta de preparo por parte dos pais e mestres, pois, não tiveram oportunidade de ter acesso a essas informações referentes a como se trabalhar sexualidade na Educação Infantil, e é por issso que hoje grande parte dos professores sofrem, por não saberem abordar essse tema em sala de aula. Porém, sabemos que a falta de preparo é apenas uma das justificativas apontadas por pais e mestres da educação, mas, com isso, sabemos, também, que cada um pode fazer a sua parte, a partir da possibilidade de buscar conhecer as especificidades do trabalho com a sexualidade na infância.
\end{abstract}

Palavras-chave: Contexto escolar. Educação Infantil. Sexualidade. Temas transversais.

\section{CHILD SEXUALITY IN THE 21ST CENTURY: BETWEEN CHILDREN AND POSSIBILITIE}

\begin{abstract}
There are many experiences in our daily lives that show us the existence of taboos and prejudices regarding sexuality in the current context, both in society and in school. These prejudices and taboos are derived from a cultural heritage that has existed since the dawn of mankind. The breaking of these taboos related to this question must be inserted in the pedagogical practices of the school context, so that discards all the fallacies

\footnotetext{
${ }^{1}$ Graduanda no curso de Licenciatura plena em Pedagogia, da Faculdade São Francisco da Paraíba (FASP). Email: raquelandrade390@gmail.com

${ }^{2}$ Pedagogoa. Especialista em Docência do Ensino Superior e Educação Infantil e Anos Iniciais do Ensino Fundamental. Mestranda em Educação. Email: thaisoliveirabst@gmail.com

${ }^{3}$ Graduanda no curso de Licenciatura plena em Pedagogia, da Faculdade São Francisco da Paraíba (FASP). Email: geaneandrade.1@ hotmail.com
} 
on the subject like something sinful. It is in this way that the present article has as purpose to raise proposals of how to work the sexuality theme in the school context, having been elaborated from a field research carried out with two subjects of research - a mother and a teacher of a municipal public school of the city of Poço José de Moura. The results show that the difficulty of having an effective work on this subject is due to a lack of preparation on the part of the parents and teachers, since, they did not have opportunity to have access to this information on how to work sexuality in the It is for this reason that today a large number of teachers suffer because they do not know how to approach this theme in the classroom. However, we know that lack of preparation is only one of the justifications pointed out by parents and masters of education, but with this, we also know that each one can do his part, from the possibility of seeking to know the specificities of work with sexuality in childhood.

Keywords: School context. Child education. Sexuality. Cross-cutting themes.

\section{SEXUALIDAD INFANTIL EN EL SIGLO XXI: ENTRE LACUNAS Y POSIBILIDADES}

RESUMEN. Son muchas las experiencias vividas en nuestro cotidiano, que nos muestran la existencia de tabús y prejuicios en relación a la sexualidad en el contexto actual, tanto en la sociedad, como en la escuela. Estos preconceptos y tabús son provenientes de una herencia cultural que existe desde los primordios de la humanidad. La ruptura de estos tabús relacionados a esta cuestión deben estar insertos en las prácticas pedagógicas del contexto escolar, de forma que descarte todas las falacias sobre el tema como algo pecaminoso. Es de este modo que el presente artículo tiene como objetivo levantar propuestas de cómo trabajar la temática de sexualidad en el contexto escolar, habiendo sido elaborado a partir de una investigación de campo realizada con dos sujetas de investigación - una madre y una profesora de una escuela pública municipal de la ciudad de Poço José de Moura. Los resultados nos muestran que la dificultad de tener un trabajo eficaz sobre esta temática, se debe a una falta de preparación por parte de los padres y maestros, pues no tuvieron oportunidad de acceder a esas informaciones referentes a cómo trabajar sexualidad en la vida Educación Infantil, y es por lo que hoy gran parte de los profesores sufren, por no saber abordar este tema en el aula. Sin embargo, sabemos que la falta de preparación es sólo una de las justificaciones apuntadas por padres y maestros de la educación, pero, con eso, sabemos, también, que cada uno puede hacer su parte, a partir de la posibilidad de buscar conocer las especificidades del trabajo con la sexualidad en la infancia.

Palabras clave: Contexto escolar. Educación Infantil. La sexualidad. Temas transversales.

RPI Revista de Pesquisa Interdisciplinar, Cajazeiras, v. 3, n. 1, 131 - 141, jan/jul. de 2018. 


\section{Introdução}

O presente artigo tem como finalidade levantar propostas de como trabalhar a temática de sexualidade no contexto escolar, sabendo que é um assunto socialmente considerado impróprio, constrangedor e vergonhoso. A quebra dessses tabús relacionados a essa questão devem está inseridos na pratica pedagógica do contexto escolar, de forma que descarte todas as falacias sobre o tema como algo pecaminoso.

Falar de sexualidade antes era algo quase inadimissível, porém no coxtexto atual essa situação está mudando, são grandes as oportunidades que o mundo proporciona as pessoas para aceitarem e lidarem melhor com sua própria sexualidade. No entanto o contexto escolar ainda sofre grandes desafios para que sejam ensinadas as crianças que a sexualidade é algo natural, digna de respeito, pois ainda é vista como algo feio, reprimido e constrangedor. Muitos educadores sentem uma grande necessidade de apoio, de orientações que os norteiem para a pratica das orientações desse contexto no âmbito escolar.

Para melhor compreendermos esse assunto, abordaremos a fala de alguns autores como (SOUZA, 1999); (LOURO, 1997) (MOIZÉS; BUENO, 2012); (FOUCAULT, 2005); que irá abordar esse tema de forma mais aberta e inteligente. Faremos uso também, das palavras de uma docente, e de uma mãe de aluno de uma escola municipal de educação infantil, abordando suas interferências sobre falar de sexualidade na educação infantil.

\section{A escola no processo de adaptação ao ensino da sexualidade infantil}

A importância de tratar de sexualidade infantil de forma clara, e responsável, sendo visto que as crianças recebem constatemente uma grande variedades de informações sobre gêreno, corpo, e sexualidade através da mídia. Porém as dúvidas não ficam esclarecidas, já que os meios de comunicação não os respondem de forma precisa. Dito isso, Souza, (1999) ressalta que:

Devido a corrida para o mercado de trabalho, os pais pouco acompanham o desenvolvimento dos filhos, que longe da companhia dos pais, ficam grande parte do dia na frente da televisão, sendo bombardeados por cenas sexuais alheias a sua realidade imediata, fazendo com que elas vejam o sexo como algo banal, sem ter consciencia do verdadeiro valor da 
sexualidade humana, desenvolvendo cada vez mais cedo seu interesse pelas atividades sexuais. (p.33)

A pouca vivencia dos pais com seus filhos fazem com que eles fiquem maior parte do tempo vendo TV, ouvindo músicas inadequadas para sua idade, sendo expostos a temática sexualidade de forma não informativa; e eles vão criando um conceito de que a sexualidade é algo banalizado. É importante que a família acompanhe e oriente seus filhos. A relação de companheirismo dos pais com a escola é fundamental para orientação das crianças. Com tantas dúvidas que as crianças possuem, algumas familias não sabem responder, ou se sabem, não vai responder esses questionamentos para seus filhos devido a educação repressora que foram estabelecidos referente a sexualidade.

Os meios de comunicação, assim como a influência da mídia, tem oferecido as crianças um novo ver sobre sexualidade, que de forma expressiva tem influenciado em seu comportamento, que por sua vez são levados para a escola. Diante de fatos irrelevantes sobre a sexualidade vista pelas crianças, a escola tem como papel guiar essas crianças para a vida cidadã de forma autônoma.

No âmbito escolar cobra-se uma nova atitude em relação aos educadores ao lidar com as dúvidas dos alunos sobre fatos relacionados a sexualidade. Dessa forma pode-se questionar de que maneira podem ser enfrentados aos desafios que são lançados a escola em relação a sexualidade infantil na atualidade. Muitos educadores deparam-se com situações onde a criança é guiada por uma "[...] vontade de saber [...]" (FOUCAULT, 2005, p.14) Faz-se impotante tratar a sexualidade infantil na escola, de forma natural e com responsabilidade. A sexualidade não está pautada somente a genitalidade, ela trata também da convivência humana, envolvendo aparências como auto-estima, sensações de encanto, amor, cordialidade. Falar sobre a sexualidade vai além dos aspcetos individuiais, pois envolve também questões culturais, sociais, psíquicas, trazendo consigo uma historia. Nas palavras de Moizés e Bueno (2012, p. 207) “A sexualidade para ser compreendida, não pode ser separada do indivíduo holístico, posto que é moldada nas relações que o sujeito estabelece, desde a mais tenra idade, consigo mesmo e com os outros."

Desse forma podemos dizer que a sexualidade está associada a infância, que é construida através de marcas culturais, que são preestabelecidas antes mesmo do individuo surgir. Fato corriqueiro, é a prefrencia do sexo do bebê antes mesmo de saber 
qual gênero é. As famílias já preestabelecem uma moldura em volta da criança que ainda nem nasceu.

A sexualidade antes era vista como algo impróprio, proibido, pecaminoso, mas tudo isso não passam de mitos, que de forma prejudicial, esconde do individuo o direito de conhecer seu proprio corpo, e de orientar-se quanto a sua sexualidade, e sua saúde mental. Nossos antecedentes nos deixou como herança cultural que a sexualidade está restrito somente ao sexo e genitalidade. Impostos ao que pode, e ao que não pode, dandonos deveres específicos para mulheres e homens, e impondo límites para ambos.

O que observamos é educadores a procura de orientações, e preparo para enfrentar os desafios que são encontrados referente a sexualidade das crianças, que aparecem frequentemente no âmbito escolar. Alguns buscam por informações, conhecimentos, e os sentimentos de angustia e constrangimentos sobre a temática aumentam, pois não sentemse preparados para trabalhar a sexualidade infantil com as crianças. A escola tem como função integrar a educação das crianças, de modo sistematizado, porém para isso é necessário que sejam orientados, tendo um preparo e planejamento para lidarem com essas situações de conflito no contexto escolar. Embora saibamos que existem muitos docentes que desconsideram totalmente a temática, pois acreditam ser algo impróprio para o desenvolvimento da criança, considerando que a mesma é pura e ingênua, para conhecer a sexualidade, em seu ponto de vista, imprópio e pecaminoso.

A educação sexual vem passando por grandes mudanças ao longo dos anos, onde são enfatizados ideologia, crenças e valores. E a escola é o norte responsável para guiar e formar o individuo a conviver em sociedade, sendo que a escola desenvolva as práticas pedagógicas voltadas a educação infantil, respeitando o contexto do aluno. A escola deve tratar a sexualidade de forma mais autônoma, e reponsável, descartando os preconceitos, dogmas e tabús relacionados a essa temática. É necessário que haja o dialogo relacionado a sexualidade, dentro da escola, pois há várias questões recorrentes sobre essa temática, não somente na mídia, e nos grupos de conversas com os amigos, mas sim, estão inseridos também na escola, pois:

[...] fazem parte das conversas dos/as estudantes, elas estão nos grafites dos banheiros, nas piadas e brincadeiras, nas aproximações afetivas, nos namoros; e não apenas aí, elas estão também de fato nas salas de aula assumidamente ou não - nas falas e atitudes das professoras, dos professores e estudantes. (LOURO, 1997, p. 131). 
Deste modo a escola deve assumir essa missão importante, de excitar o pensamento das crianças e jovens, de acordo com as problematizações e diálogos sobre as diversas temáticas sobre sexualidade no meio social. Pois, efetivando-se um trabalho de orientação sexual na contexto escolar permite que os alunos tenham informações e reflexões sobre todos os aspectos que submergem a temática sexualidade. Fazendo com que os mesmos se tornem, responsáveis, e encarem a sexualidade de forma sadia e pura, abolindo com os preconceitos e desrespeito, relacionados a temática.

\section{Metodologia}

A pesquisa é de carácter qualitativa, e podemos ressaltar que esse tipo de pesquisa surgiu na antropologia, de modo entre meio natural, e com bases na sua tradição antropológica ficou sendo vista como uma investigação etnografica, popularmente considerada um estudo feito da cultura. Como algumas de suas denominações podemos dirigir-se como:

A pesquisa qualitativa é conhecida também como "estudo de campo", "estudo qualitativo", "interacionismo simbólico", "perspectiva interna", "interpretativa", "etnometodologia", "ecológica", "descritiva", "observação participante", "entrevista qualitativa", "abordagem de estudo de caso", "pesquisa participante", "pesquisa fenomenológica", "pesquisa-ação", "pesquisa naturalista", "entrevista em profundidade", "pesquisa qualitativa e fenomenológica", e outras [...]. Sob esses nomes, em geral, não obstante, devemos estar alertas em relação, pelo menos, a dois aspectos. Alguns desses enfoques rejeitam total ou parcialmente o ponto de vista quantitativo na pesquisa educacional; e outros denunciam, claramente, os suportes teóricos sobre os quais elaboraram seus postulados interpretativos da realidade (TRIVIÑOS, 1987, p. 124).

Este artigo foi direcionado através da disciplina de Educação e Sexualidade, no curso de licenciatura plena em Pedagogia, em uma turma de $4^{\circ}$ período da Faculdade São Francisco da Paraíba- FASP. Para o valimento de informações, foi feito uma pesquisa de campo com uma professora e uma mãe de aluno de uma escola de rede municipal, da cidade de Poço de José de Moura, localizada no alto sertão paraíbano. Ao retrartarmos de uma entrevista, Rosa e Arnoldi (2006) dizem que:

A entrevista é uma das técnicas de coleta de dados considerada como sendo uma forma racional de conduta do pesquisador, previamente estabelecida, para dirigir com eficácia um conteúdo sistemático de conhecimentos, de maneira mais completa possível, com o mínimo de esforço de tempo. (p17.)

RPI Revista de Pesquisa Interdisciplinar, Cajazeiras, v. 3, n. 1, 131 - 141, jan/jul. de 2018. 
A entrevista ocorreu na escola de educação infantil, com uma docente, e com uma mãe de uma das crianças. Para cada uma delas, foram lançadas 5 perguntas, onde elas puderam através de um diálogo retratar sobre o ensino de sexualidade Infantil com as crianças. Onde pautaram sobre as dificuldades que existem ao trabalhar essa temática na Ed.Infantil, como também falaram sobre as possibilidades de novas estratégias para facilitar o debate da temática com as alunos.

\section{Resultados e discussão}

Em um primero momento, preguntamos a uma professora de Educação Infantil, e a um mães, de que modo elas enxergam a importância de trabalhar a temática sexualidade em sala de aula. E de que forma isso implicaria no desenvolvimento das crianças. E a todo momento sentiram seguras e confiantes se posicionando aos questionamentos. Visto que existe a incompatibilidade de pensamentos entre a professora e a mãe, em relação a essa temática.

Em relação as respostas da professora, ela nos afirma o tema sexualidade é muito importante, para que as crianças não criem preconceitos entre os sexos, e possam conhecer melhor o seu corpo, para terem um bom desenvolvimento sexual de forma saudável e com responsabilidade. Diz também que é difícil trabalhar esse tema no contexto escolar, pois o principal desafio que a escola enfrenta com relação a trabalhar sexualidade infantil, é a falta de preparação dos professores, que se afligem com as perguntas dos alunos sobre esse tema, como também a família, que por falta de conhecimentos não aceitam que a sexualidade infantil seja trabalhada no contexto escolar. Ao posicionar-se a fala da professora uma das mães nos responde que:

[...] a temática é bastante complexa para trabalhar com as crianças na escola, no entanto a escola pode contribuir realizando palestras, encontros com pais e mães para abordar esta temática, para que os mesmos tenham conhecimento do que se trata, e assim, possam tomar as devidas precauções para seus filhos e filhas. [...] o tema deverá ser trabalhado no contexto escolar, com uma equipe de profissionais capacitados na área para discutir a temática com os pais, de forma a contribuir com o diálogo entre pais e filhos da melhor maneira possível. (Mãe Carlota) 
Para esta mãe, se faz necessário a participação de profissionais habilitados para desempenhar essa função de orientar as crianças sobre sexualidade, onde a escola deve incluir a participação da família, debater e esclarecer tudo o que pretende ser passado para as crianças. Para Sayão (1997) ela ressalta que que a sexualidade no contexto escolar necessita acontecer de modo que associe, levado em consideração suas extensões de modo que:

o trabalho em orientação sexual deve ser iniciado com o profissional que se sentir disponível para tal, requisito necessário mas não suficiente. Não há necessidade de habilitação desse profissional na área biológica, uma vez que o fundamental é a postura do professor, sua capacidade de reconhecer como legítimas a questões dos alunos, acolhendo-as com respeito. [...] $\mathrm{O}$ fundamental para a preparação do profissional da educação em orientação sexual é a sua formação em temas afins à sexualidade. $\mathrm{O}$ educador interessado deve entrar em contato com as questões teóricas, leituras e discussões sobre as temáticas específicas e suas diversas abordagens, assim como ter acesso a um espaço grupal de supervisão do trabalho realizado (p. 115).

Abrangendo as palavras da autora, sobre a importância de profisisonais para orientar sobre educação e sexualidade, conexo ás exterioridades propostas é aceitável lembrarmos, que vivenciamos uma sociedade repleta de conhecimentos a serem oferecidos, e qualquer educador pode abranger esse tema, desde que se sinta capacitado para abranger esse tema, de modo que busque se adentrar em novos conhecimentos, especificos para sentir firmeza ao debater essa temática com os alunos. A conjectura a qual chegamos é que, em maioria dos casos é a falta pela busca de conhecimentos que interfere para trabalhar gênero e sexualidade na nossa atualidade.

O que podemos perceber, é que as escolas, não estão trabalhando de forma adequadada, ao que se diz respeito a gênero e sexualidade, tudo isso porque, possuem dificuldades para lidar com essa temática em seu dia-a-dia, desse modo é necessário que a escola estabeleça uma nova metódologia de trabalho educativo que favoreça a todos os educandos. Em consideração a essas dificuldades encontradas no âmbito escolar, continuarmos com a entrevista onde perguntamos a professora quais metodologias, ela acha serem necessárias para abordar essa temática no contexto escolar. E habilmente ela nos diz que para trabalhar sexualidade com as crianças é "Interessante que o tema seja trabalhado em rodas de conversas, exibição de filmes relacionados de acordo com a faixa etária da criança, com imagens e/ou desenhos, e também com mini-palestras". Ao 
analisarmos a resposta da docente, podemos perceber que ela considera importante, a exploração da temática, de modo que as crianças possam perceber que a sexualidade está em nosso meio, onde há exibição em filmes, desenhos, assim como também não descarta a importância de mini-palestras relacionadas ao tema, aqui poderiam ser debatidos assuntos como a pedofilia, abuso sexual as crianças, a violencia contra LGBT'S, gravidez precoce, etc.; Braga (2010) nos diz que:

A escola pode deixar de ser um espaço de opressão e repressão na questão da sexualidade, para se tornar um ambiente efetivamente seguro, livre e educativo para todas as pessoas. E, hoje, não é mais possível que as questões relativas à sexualidade passem despercebidas ou que sejam tratadas com deboche ou indignação moral. E os/as pedagogos/as têm uma importante ação nesse sentido (p.280)

A participação dos professores nesse aspecto, é indispensável, pois a orientação dos mesmos com as crianças, servirão como suporte para amadurecer seus pensamentos e conceitos em relação a sexualidade, onde em muitas ocasiões é vista por eles de forma debochada, alvo de críticas, e exposta ao desrepeito. Fazendo relação com a fala do autor, a professora nos disse que o modo como abordaria as manifestações da sexualidade de seus alunos, no seu cotidiano e na sala de aula, assim como nos espaços escolares, seria de forma simples e eclarecedora, por meio de conversas, e respondendo apenas o necessário de acordo com a faixa etária dos alunos, forneceria as informações necessaria e norteando em relação as dúvidas. Já em relação a forma como a mãe trabalharia essa temática com seu filho, ela nos repondeu que seria através do dialogo relatando suas vivências e experiências, passando para seus filhos a confiança e segurança, para que eles pudessem se sentir a vontade para tratar de qualquer assunto.

\section{Conclusão}

O presente artigo teve como finalidade falar sobre as dificuldades que os educadores sofrem em trabalhar com a temática de gênero e sexualidade infantil no âmbito escolar nos dias atuais, considerando que é de suma importância que se discuta esta temática no âmbito escolar. Onde foi possível perceber que as dificuldades enfrentadas pelos docentes, em abordar esse tema com seus alunos, ocorre pela falta de informação, que eles não possuem para discutir as temáticas sem temores e preconceitos. 
Desse forma, o que se consta, é que a dificuldade de se ter um trabalho eficaz sobre esta temática, deve a maioria dos educandores, pois não tiveram oportunidade de ter acesso a essas informações referentes a como se trabalhar sexualidade na educação infantil, e é por issso que hoje grande parte dos professores sofrem, por não saber abordar essse tema em sala de aula.

A necessidade de refletir sobre o que acontece em rosa sociedade, onde exige a maior precisão de os professores buscarem formações concisas para debater com seus alunos, pois questionar as atribuições quanto ao gênero e à sexualidade, são assuntos que estão relacionadas e vivenciadas no contexto escolar. Deste modo, esperamos que o presente artigo, permita ao profisisonais da educação, a ampliação pelas informações, para se trabalhar a temática sexualidade infantil no contexto escolar, de forma que levem para seus alunos, reflexões e discussões sobre as dúvidas que se manifestam entre os alunos, ou no contexto famíliar e, principalmente, na Educação Infantil.

\section{Referências}

BRAGA, Eliane Rose Maio; SPIRITO, Carmem Alcaide. Una invetigación sobre la importância de la educación afectivo-sexual en las escuelas. Revista IberoAmericana de Estudos em Educação, 2010, pp.18-36.

FOUCAULT, Michel.História da sexualidade I: a vontade de saber. Rio de Janeiro:Edições Graal, 1997.(Biblioteca de Estudos Humanos. Saber e Sociedade, $\mathrm{n}^{\circ}$ 2). _ Não ao sexo rei. IN:Microfisica do poder.Tradução e organização de Roberto Machado.Rio de Janeiro: Graal, 1979.p.229242. A ordem do discurso. 12.ed. São Paulo:Loyola,2005.

\section{LOURO, G. L., Gênero, Sexualidade e Educação: uma perspectiva pós- estruturalista.}

Petrópolis: Vozes, 1997.

ROSA, Maria Virgínia de Figueiredo Pereira do Couto; ARNOLDI, Marlene Aparecida Gonzalez Colombo. A entrevista na pesquisa qualitativa: mecanismos para a validação dos resultados. Belo Horizonte: Autêntica Editora, 2006. 112 p.

SAYÃO, Yara. Orientação sexual na escola: os territórios possíveis e necessários. In: AQUINO, Júlio Groppa. Sexualidade na escola: alternativas teóricas e práticas. São Paulo: Summus, 1997, pp.107- 118. 
SOUSA, Marilena Batista. Orientação Sexual na Escola: os anseios dos jovens. 1999.74f.Monografia(graduação em pedagogia)Faculdade de fisolofia Dom Aureliano Matos. Universidade Estadual do Ceará, Limoeiro do Norte

TRIVIÑOS, Augusto Nibaldo Silva. Três enfoques na pesquisa em ciências sociais: o positivismo, a fenomenologia e o marxismo. In: . Introdução à pesquisa em ciências sociais. São Paulo: Atlas, 1987. p. 31-79. 